\title{
Ergenlerde Duygusal Zekâ, Mutluluk Korkusu ve Mizah Tarzları Arasındaki Yordayıcı İlişkinin İncelenmesi
}

DOI: $10.26466 /$ opus.694580

\author{
*Zafer Baş - **Ayşegül Baş - *** Ahmet Kalafat- ****Bülent Dilmaç \\ ${ }^{*}$ Uzm. Psk. Dan., Akif İnan Anadolu İmam Hatip Lisesi, İstanbul/Türkiye \\ E-Posta: zaferrbas@hotmail.com \\ ORCID: $\quad$ 0000-0001-8000-9416 \\ ** Uzm. Psk. Dan., TOKİ Hayme Ana Mesleki ve Teknik Anadolu Lisesi, İstanbul/Türkiye \\ E-Posta: ayseakdeniz43@gmail.com ORCID: 0000-0003-3720-6590 \\ *** Uzm. Psk. Dan., Tekirdağ Saray Mesleki ve Teknik Anadolu Lisesi, Tekirdağ/Türkiye \\ E-Posta: ahmet.kalafat28@hotmail.com ORCID: 0000-0002-8492-4870 \\ **** Prof. Dr., Necmettin Erbakan Üniversitesi,Ereğli Eğitim Fakültesi, Konya/Türkiye \\ E-Posta: bulentdilmac@gmail.com \\ ORCID: $\underline{0000-0001-5753-9355}$
}

\begin{abstract}
Öz
İnsan yaşamının önemli bir geçiş dönemi olan ergenlik dönemi beraberinde birçok değişimi de getirmektedir. Bu süreçte bireyin duyguların tanıması ve duyguların yönetebilmesi oldukça büyük önem taşımaktadır. Mutluluk ise bu gelişimsel dönemde bireylerin arayışında olduğu bir olgudur. Fakat bazı bireylerde mutlu olmanın bazı olumsuz sonuçlar doğuracă̆ına ilişkin inançların olması mutluluk korkusu olarak adlandırdığımız bir kavramı ortaya çıkarmıştır. Mutluluk korkusu aynı zamanda ergenlerde mizah tarzların da etkilemektedir. Yapılan bu çalışmada ergenlerde duygusal zekâ, mutluluk korkusu ve mizah tarzları arasındaki yordayıcı ilişkinin incelenmesi amaçlanmıştır. A raştırmanın çalışma grubunu İstanbul ilinde eğitim gören 14- 18 yaş aralığındaki 226 lise öğrencisi oluşturmaktadır. Araştırmada veri toplama aracı olarak Duygusal Zekâ Özellik Ölçeği-Kısa Formu, Mutluluk Korkusu Ölçeği Mizah Tarzları Ölçeği kullanılmıştır. Ergenlerin duygusal zekâları ile mizah tarzları arasındaki yordayıcı ilişkiler incelendiğinde, pozitif yönde anlamlı doğrusal bir ilişkinin olduğu görülmüştür. Bir başka ifadeyle elde edilen bulgular, ergenlerde mizah duygununun artmasıla duygusal zekâsında da artış olacağını göstermektedir. Ergenlerin mutluluk korkuları ve duygusal zekâları arasındaki yordayıcı ilişkiler incelendiğinde, negatif yönde doğrusal ve anlamlı bir ilişki olduğu görülmüştür. Diğger bir ifadeyle elde edilen bulgular, ergenlerin duygusal zekâları arttıkça mutluluk korkularının azalacağını ortaya koymaktadır.
\end{abstract}

Anahtar Kelimeler: Duygusal Zekâ, Mutluluk Korkusu, Mizah Tarzları, Ergenlik. 


\title{
Investigation of the Predictive Relationship Between Emotional Intelligence, Fear of Happiness and Humor Styles in Adolescents
}

\begin{abstract}
Adolescence, which is an important transition period of human life, brings many changes with it. In this process, it is very important for the individual to recognize and manage their emotions. Happiness is a phenomenon that individuals seek in this developmental period. However, the belief that being happy will have some negative consequences in some individuals has revealed a concept we call fear of happiness. Fear of happiness also affects the humor styles of adolescents. In this study, it was aimed to examine the predictive relationship between emotional intelligence, fear of happiness and humor styles in adolescents. The study group of the research consists of 226 high school students between the ages of 14 and 18 studying in Istanbul. Emotional Intelligence Trait Scale-Short Form, Fear of Happiness Scale, Humor Styles Scale were used as data collection tools in the study. When the predictive relationships between the emotional intelligence and humor styles of adolescents were examined, it was seen that there was a positive and significant linear relationship. In other words, the findings show that emotional intelligence will increase as the sense of humor increases in adolescents. When the predictive relationships between adolescents' fear of happiness and emotional intelligence were examined, it was seen that there was a negative linear and significant relationship. In other words, the findings reveal that as the emotional intelligence of adolescents increases, their fear of happiness will decrease.
\end{abstract}

Keywords: Emotional Intelligence, Fear of Happiness, Humor Styles, Adolescence 


\section{Giriş}

İnsanoğlu var olduğu günden beri çevresindekilerle bir iletişim halindedir. Sosyal bir varlık olan insan diğer canlılardan farklı olarak bir iradeye ve kullanabileceği bir akla sahiptir ve bunlar sayesinde yaşama uyum sağlaması ve hayatta kalabilmesi daha mümkündür. Bu uyum süreci içerisinde kişinin bilişsel zekasından ziyade sahip olduğu duygusal zekası da oldukça önemlidir. Duygular hayatın anlamı ve değeri için, karar verme ve bu kararları uygulama aşamasında rehberlik edici bir işleve sahiptir (Özdemir, 2015).

Duygu "belirli bir nesne, olay ve bireylerin insanın iç dünyasında bıraktığı izlenim" şeklinde tanımlanmaktadır (TDK, 2019). Goleman duyguların akılcı zihin işleyişine katkı sağladığını, akılcı zihnin ise duygusal verilerin şekillendirdiğini veya bazen de reddettiğini dile getirmiştir(Goleman, 2000). Zeka ise bilginin öğrenildiği ve kaydedildiği, ilişki kurularak yorumlandığı, kaydedildiği, akıl yürütme, algılama, çağrışım yapabilme ve sezebilme gibi yetileri olan beyne ait bir kapasite olarak tanımlanmaktadır (Yerli, 2009). Buradan yola çıarak duygusal zeka kavramı en basit şekliyle duyguların akıllıca kullanılması halidir (Çakar ve Arbak, 2004). Weisinger'e (1998) göre duygularımızı kullanarak davranışlarımızı şekillendirebilir, yön verebilir ve olumlu sonuçlar elde edebiliriz. Duygusal zeka kavramı ilk olarak Mayer ve Salovey tarafından kullanılmıştır. Duygusal zekayı bireylerin kendisinin ve çevresindekilerin duygularını gözlemleme becerisini, duyguları ayırt edilebilmesini ve duygularını anlayıp öğrendiği bilgiyi düşünce ve davranışlarına aktarabilmeyi içeren bir sosyal zeka türü olarak tanımlamışlardır (Mayer ve Salovey, 1993).

Duygular genellikle karmaşık bir halde gelirler. Mesela mutlulukla beraber suçluluk, öfkeyle beraber korku gibi birçok duygunun karşıtıyla birlikte ortaya çıktığını görmekteyiz. Bundan dolayı duyguların aralarındaki karmaşıklığı ve değişiklikleri tanımlayabilme becerisi gereklidir (Çakar ve Arbak, 2004). Bireyin duygularını tanıyı doğru bir biçimde yönetebilmesi aynı zamanda yaşamdan doyum almasına, yaşam kalitesinin artmasına, hayata daha pozitif bir gözle bakmasına ve dolayısıyla mutlu olmasına sebep olmaktadır (Furnharn ve Petrides, 2003).

Mutluluk kavramı genel olarak bireyin içinde bulunan tatmin duygusu veya durumu olarak tanımlanabilmektedir (Uichida ve Oishi, 2016). 
Mutluluk güven, neşe, haz ve tatmin gibi olumlu duyguları içinde barındıran pozitif duygulanımın yüksek olduğu öfke, hayal kırıklığı, üzüntü, nefret, yetersizlik, acizlik gibi olumsuz duygulanımın daha düşük bir seviyede olduğu bir duygu durumu olarak tanımlanmaktadır (Diener, 1994). Bir başka tanımda ise, mutluluğun yaşam kalitesi ve öznel iyi oluş ile aynı anlamda kullanıldığını ifade edilmektedir (Veenhoven, 2006). Yine benzer şekilde, mutluluğun psikoloji alanındaki karşılığının öznel iyi oluş olduğu belirtilmektedir (Yiğit, 2013).

Öznel iyi oluş ile ilgili yapılan çalışmalar genel olarak olumlu duyguların varlığı üzerinedir. Mutluluk kavramı olumsuz duygulardan bağımsız olarak ele alınmaktadır (Joshanloo, 2014). Fakat mutluluk, sevgi ve sevinç gibi duygular her zaman bireye haz vermez, korkulan olumsuz duygular olarak da değerlendirilebilmektedir. Beraberinde mutluluk korkusu kavramını ortaya çıkarmaktadır (Gilbert ve ark. 2014).

Yapılan bir çalışmada, farklı kültürlerden bireylerin birbirinden farklı nedenlere bağlı olarak mutlu hissetmekten veya mutlu olmaktan kaçma eğilimi gösterdiklerini ifade etmektedirler. Bunun nedenlerinden biri fazla mutlu olmanın kötü sonuçları beraberinde getireceği inancıdır. Çok mutlu olmanın veya çok neşeli olmanın ardından olumsuz bir durumla karşılaşma olasılığının yüksek olduğu düşüncesidir (Joshanloo ve Weijers, 2014). Buradan yola çıarak Joshanloo (2014), mutluluk korkusu kavramını ortaya koymuş ve mutluluk korkusunu mutluluğun bazı negatif sonuçlara sebep olabileceğine ve bundan dolayı bu durumlardan kaçınılmasının doğru olduğuna inanılan bir duygu şeklinde tanımlamıştır.

Alan yazın incelendiğinde, araştırmacıların mutluluk korkusuna sebep olan bazı durumları şu şekilde ifade ettikleri görülmüştür. Çocuğun eğlendiği ya da olumlu bir duygu içerisinde olduğu anlarda ceza veya tehditle karşılaşmasının, mutsuz ve huzursuz bir ailesinin olmasının, ebeveynlerinden herhangi birinin hasta olduğu bir yerde eğlenen çocuğun aldığı keyif ve zevk için kendini suçlu hissetmesinin gerekli olduğuna duyulan inanç veya erken dönem uyumsuz şemalara sahip olmasının mutluluk korkusuna sebep olabileceği ifade edilmiştir. Bununla beraber, nazar gibi bazı kültürel inanışların, toplumda bu konulara dair var olan inançların ve benzer dini değerlerin de mutluluktan korkmanın altında yatan nedenlerden olabileceği savunulmaktadır (Gilbert ve ark., 2014). Aynı zamanda mutluluktan korkmaktan ziyade bu mutluluğu göstermek ve ifade etmeye yönelik bir çekin- 
menin olduğuna inanılmaktadır. Örneğin Asya kültüründe yaygın bir biçimde bazı zamanlarda ve durumlarda mutluluk hoşa gitmeyen özellikle de korkulan bir duygu olarak görülmektedir (Joshanloo ve ark. 2014).

Bireylerin gelişimleri açısından duygusal zeka ve yaşam doyumu ve bununla beraber ortaya çıkan mutluluk düzeyleri birbirini etkileyen ve birbiri ile ilişkili değişkenler olarak karşımıza çıkmaktadır. Bu değişkenlerin yanında önemli olan bir diğer değişken ise, kişilerin hayata pozitif ve anlamlı bakmasını, mutlu olmasını ve psikolojik iyi oluşa ulaşmasını sağlayan mizahtır (Tümkaya, Hamarta, Deniz, Çelik ve Aybek, 2008). Gülmek ve mizah bireyin psikolojik ve fizyolojik sağlığı açısından önemli bir etkendir. Bununla beraber bireyin mutlu olmasında da büyük bir paya sahiptir (Martin, 2001).

Mizah kelimesi arapça bir kelime olup şaka, şaka yapma sözcüklerinden türetilmiştir. Osmanlıca-Türkçe Ansiklopedik sözlügünde mizah kavramı, düşünce ve duyguların güldürücü bir anlatımla dile getirilme sanatı şeklinde tanımlanmaktadır (Özdemir, Sezgin, Kaya ve Recepoğlu, 2011). Aynı şekilde bir başka tanımda da mizah beklenmedik bir zamanda ve beklenmeyen bir biçimde ortaya çıkan bir durum olarak tanımlamıştır (Oral, 1998). Bununla beraber mizahın eleştirel bir tepki türü olduğunu dile getirmiştir. Mizah yaşamın gülünen ve saçma yanlarını gösterme sanatı olarak bir yandan güldürmeyi amaçlarken bir yandan da hayatın gerçeklerini göstermektedir (Oruç, 2010).

Mizahta farklı birçok duygu bir aradadır. Alay etme, öfke, küçümseme, mutluluk gibi duygular insanlar arasında ilişkilerde mizah ile yansitılır. Yapılan çalışmalar dört farklı mizah tarzının var olduğunu göstermektedir (Martin, 2003). Bunlardan ikisi uyumlu, ikisi uyumsuzdur. Bunlar; katılımc1 mizah, kendini geliştirici mizah, saldırgan mizah ve kendini yıkıcı mizahtır. Katılımcı mizahta bireyler kişilerarası ilişkilerine zarar vermeyecek ve ilişkilerini daha da kuvvetlendirecek biçimde mizahı kullanırlar. Kişilerarası anlaşmazlıkların azalmasına ve ilişkilerin daha da kolaylaşmasına katkı sağlarlar (Martin ve ark., 2003). Kendini geliştirici mizaha sahip kişiler ise, sıkıntılı ve stresli bir olay yaşarken esprili yapıları sayesinde bu olaylardan rahatlıkla kurtulabilmektedirler. Saldırgan mizah olarak adlandırılan mizah tarzı ise, bireyin yalnızca üstün olma ve haz duyma gibi kendi ihtiyaçlarını karşılayabilmek için mizahı başkaları üzerinde uygunsuz kullanmasıdır. 
Kendini yıkıcı mizah da bireyin kendi ihtiyaçlarını dahi dikkate almadan kullandığı mizahtır (Martin, 2003).

Duygusal zeka son dönemlerde oldukça fazla ilgi gören ve çalışmaların yoğun yapıldığı bir alan olarak görülmekte ve özellikle ülkemizde duygusal zekanın yaşam doyumu, iyi oluş veya öznel iyi oluş ile birlikte çalışmalarına çok fazla rastlanmaktadır. Fakat mutluluk korkusu üzerinde yeterince çalışmanın olmaması alanyazın için önemli bir eksik olduğu düşünülmüştür. Bu çalışmada daha önceki çalışmalardan farklı olarak; mutluluk korkusunun ergenlerin duygusal zeka düzeylerini ne ölçüde etkilediği incelenmiştir. Araştırmanın bu bakımdan özgün olduğu ve ergenlerde duygusal zeka kavramına kuramsal açıdan katkı sunacağı söylenebilir. Bu çalışma ergenlerin duygusal zeka düzeylerinin arttırılması ile ilgili yapılacak araştırmalarda dikkate alınması gereken faktörlerin ortaya konulması bakımından da önem arz etmektedir.

Yapılan araştırmanın amacı, ergenlerin duygusal zeka, mutluluk korkusu ve mizah tarzları arasındaki yordayıcı ilişkilerin incelenmesi olarak belirlenmiştir. Buna bağlı olarak araştırma soruları aşağıda sıralanmıştır.

1. Ergenlerin duygusal zeka düzeyleri ile mutluluk korkuları arasında yordayıcı bir ilişki var mıdır?

2. Ergenlerin duygusal zeka düzeyleri ile mizah tarzları arasında yordayıcı bir ilişki var mıdır?

3. Ergenlerin mutluluk korkuları ile mizah tarzları arasında yordayıcı bir ilişki var mıdır?

\section{Yöntem}

Bu bölümde araştırma modeli, çalışma grubu, veri toplama araçları ve toplanan verilerin analizi başlıklarına yer verilmektedir.

\section{Araştırma Modeli}

Nicel araştırma paradigmasına sahip bu çalışmada, ergenlerde duygusal zeka, mutluluk korkusu ve mizah tarzları arasındaki ilişkilerin belirlenmesi ve bu değişkenler aralarındaki ilişkilerin yapısal eşitlik modeli yoluyla s1nanması amaçlanmaktadır. Bu amaca bağlı olarak araştırmada, genel tarama modelinin bir alt çeşidi olan ilişkisel tarama modeli kullanılmıştır. 
Genel tarama modelleri, çok sayıda elemandan oluşan bir evrende, evrenin tamamı ya da evrenden alınacak örneklem ya da bir grup örnek üzerinde, evren ile ilgili genel bir yargıya ulaşmak amacıyla yapılan tarama araştırmalarıdır. Genel tarama modelleri tekil veya ilişkisel taramalar yapmaya olanak sağlar(Karasar, 2015). İlişkisel tarama modelleri, iki veya daha fazla sayıdaki değişken arasındaki değişimin birlikte var olup olmadığını veya bu değişimin derecesini ortaya koymayı amaçlayan araştırma modelleridir (Karasar, 2015).

\section{Çalışma Grubu}

Araştırmanın çalışma grubunu İstanbul ‘da farklı liselerde öğrenim gören 136'sı k1z, 90'1 erkek toplam 226 öğrenciden oluşmaktadır. Aynı zamanda çalışmaya katılan öğrencilerin yaş ortalaması 15,903'tür.

Tablo 1. Katılımcıların Cinsiyete Göre Dağılımı

\begin{tabular}{lll}
\hline Cinsiyet & Frekans & Yüzde \\
\hline Kız & 136 & 60.2 \\
Erkek & 90 & 39.8 \\
Toplam & 226 & 100 \\
\hline
\end{tabular}

Tablo-1'de görüldüğü üzere araştırmada katılımcllarının 136'sı (\% 60.2) kadın, 90'1 (\%39.8) erkektir.

\section{Veri Toplamada Kullanılan Ölçme Araçlan}

Araştırmada veri toplama araçları olarak Duygusal Zekâ Özellik ÖlçeğiKısa Formu, Mutluluk Korkusu Ölçeği ve Mizah Tarzları Ölçeği kullanılmıştır. Aynı zamanda katılımcıların demografik özelliklerini belirlemek için kişisel bilgi formu kullanılmıştır.

Kişisel Bilgi Formu: Katılımcıların cinsiyet, yaş, eğitim seviyesi, anne ve baba eğitim durumlarını belirlemek için araştırmacılar tarafından hazırlanan kişisel bilgi formu kullanılmıştır.

Duygusal Zeka Özellik Ölçeği- Kısa Formu (DZÖÖ-KF): Petrides ve Furnham (2000) duygusal zekayı, kişisel karakter özelliği şeklinde temel alınarak geliştirilmiştir. Bireyin duygusal yeterlilikleriyle ilgili kendini algılama seviyesini belirlemek amacıyla geliştirilmiş bir ölçektir. Petrides ve Furnham tarafından geliştirilmiş, TEIQue'nin uzun formuna dayanmaktadır (Petrides 
ve Furnham, 2003). Toplam 20 maddeden oluşmakta ve toplam duygusal zeka özelliğini ölçmek üzere belirlenmiş 7'li (1: Kesinlikle katılmıyorumdan, 7: Kesinlikle katılıyorum'a doğru devam eden) Likert tipi bir ölçektir. “Öznel iyi oluş", "Duygusallı", "Öz kontrol” ve "Sosyallik” olarak belirlenen 4 alt ölçekten oluşmuştur. Türkçeye uyarlaması Deniz, Özer ve Işık tarafından 2013 yılında yapılmıştır.

Ölçeğin yapı geçerliğini belirlemek amacıyla yapılan Açıklayıcı Faktör Analizi sonucunda, 20 maddeden oluşan dört faktörlü bir yapı elde edilmiştir. Elde edilen bu yapının örneklem verisine iyi uyum gösterip göstermediğini anlamak amacıyla yapılan Doğrulayıcı Faktör analizi sonucunda ise ölçeğin uygulandığı örnekleme uyumunun iyi olduğu ortaya çıkmıştır. DZÖÖ-KF'nun iç tutarlılık güvenirlik katsayısı ölçeğin tamamı için .81, testtekrar test güvenirlik katsayısı ise .86 olarak bulunmuştur. Bu sonuçlar doğrultusunda DZÖÖ-KF'nun Türkçe formunun geçerli ve güvenilir bir ölçme aracı olduğu belirlenmiştir. Güvenirlik için yapılan analizlerde DZÖÖKF'nun Cronbach alfa katsayıları İyi Oluş faktörü için .72, Duygusallık için .66, Öz kontrol için .70, Sosyallik için .70 ve ölçeğin tamamı için .81 olarak ortaya konmuştur.

Mutluluk Korkusu Ölçeği (MKÖ): Joshanloo (2013) mutlu olmanın bazı kötü /olumsuz sonuçlar doğuracağına dair inançları ölçmek amacıyla Mutluluk Korkusu Ölçeği'ni (MKÖ) geliştirmiştir. Ölçeğin Türkçeye uyarlaması Demirci, Ekşi, Kardaş ve Dinçer tarafından 2015 yılında yapılmıştır. Ölçek 5 maddeden oluşmakta ve 7'li (1= Hiç Katılmıyorum, 7= Tamamen Katılıyorum) bir derecelendirmeye göre puanlanmaktadır. Ölçekten alınabilecek puanlar 7 ile 35 arasında değişmektedir ve puanlar yükseldikçe mutluluk korkusunun arttığı varsayılmaktadır. Ölçeğin güvenirliği ise iç tutarlılık katsayısını hesaplama yöntemiyle incelenmiş ve cronbach alfa katsayısı 0.89 olarak tespit edilmiştir. Bu katsayı ölçeğin güvenilir olduğunu göstermektedir. Türkçe'ye uyarlanan bu ölçeğin, ölçeğin orijinali ile aynı faktör yapısına sahip olduğu tespit edilmiştir. Ölçeğin iç tutarlılık katsayısı .89 olarak belirlenmiştir. Doğrulayıcı faktör analizi sonucuna bakıldığında ölçeğin iyi uyum değerlerine sahip olduğu görülmektedir. Ölçeğin Cronbach alpha güvenirlik katsayısı ise .88 olarak hesaplanmıştır. 
Mizah Tarzları Ölçeği (Humor Styles Questionnaire): Mizah Tarzları Ölçeği, mizahın günlük hayattaki kullanımında bireysel farklılıklara ilişkin dört boyutunu ölçmek amacı ile geliştirilmiştir (Martin, Puhlik, Doris, Larsen, Gray ve Weir, 2003). Türkçe 'ye uyarlaması ise Yerlikaya (2003) tarafından yapılmıştır. Ölçek içerisinde iki tane uyumlu alt boyut, iki tane de uyumsuz alt boyut olmak üzere dört farklı mizah tarzını barındırmaktadır. Bu alt boyutlar; kendini geliştirici mizah, katılımcı mizah, saldırgan mizah ve kendini yıkıcı mizah olarak adlandırılmaktadır. A: Kesinlikle katılmıyorum, B: Katılmıyorum, C: Biraz Katılmıyorum, D: Kararsızım, E: Biraz Katılıyorum, F: Katılıyorum, G: Tamamıla katılıyorum arasında değişen yedili Likert tipi bir derecelendirme kullanılmaktadır. Ölçekten 7-56 puan aralığında bir puan alınmaktadır. Alt ölçeklerden alınan puanların yüksek olması ilgili olan mizah tarzının kullanımının sık olduğunu göstermektedir. Ölçeğin Türkçe'ye uyarlama çalışmasında her alt ölçeğe dair elde edilen Cronbach alfa iç tutarlık katsayıları; Katılımcı Mizah için, .74, Saldırgan Mizah için .69, Kendini Geliştirici Mizah için, .78 ve Kendini Yıkıcı Mizah için .67 olarak hesaplanmıştır (Yerlikaya, 2003).

\section{Verilerin Toplanması}

Ölçekler, amaçlı örnekleme yöntemi ile tespit edilen katılımcılara araştırmacılar tarafından uygulanmıştır. Ölçekler İstanbul'da Başakşehir ilçesinden Toki Hayme Ana Mesleki ve Tteknik Anadolu Lisesi, Başakşehir Borsa İstanbul Mesleki ve Teknik Anadolu Lisesi ve Kayaşehir Anadolu Lisesinde öğrenim gören öğrencilere uygulanmıştır. Araştırma çalışma grubunu 14 yaş ile 18 yaş arası öğrenciler oluşturmaktadır. Ölçekler uygulanmadan önce katılımcılara araştırmanın amacı ve ölçeklerin nasıl uygulanacağına dair kısa bilgi verilmiştir. Ölçeklerin uygulanması sırasında gönüllülük ilkesine bağlı kalınmıştır.

\section{Verilerin Analizi}

Araştırma, ergenlerde duygusal zekâ çerçevesinde mutluluk korkuları ve mizah tarzları arasındaki ilişkilerin belirlenmesi ve bu değişkenler aralarındaki ilişkilerin yapısal eşitlik modeli ile incelenmesi amacıyla yapısal eşitlik modeli analizi yapılmıştır. Yapısal eşitlik modellemesi kuramsal bir modeli analiz etmek için gözlemlenen ve değişkenler arası karşılıklı ve nedensel 
ilişkileri ortaya çıkaran bir istatistiksel yaklaşımdır (Shumacker ve Lomax, 2004). Yapısal eşitlik modeli analizi AMOS 19 programı ile yapılmıştır.

Aynı zamanda toplanan verilerin yüzde ve frekans hesaplamaları SPSS 18 programı ile gerçekleştirilmiştir.

\section{Bulgular}

Elde edilen modelde $\left(\mathrm{x}^{2} / \mathrm{sd}=2.58, \mathrm{p}<.001\right)$ dört exogenus, mizah (kendini geliştirici mizah, katılımcı mizah, saldırgan mizah ve kendini yıkıcı mizah) bir endogenous mutluluk korkusu veri bulunmaktadır. Modelde görülen tüm yolların istatistiksel olarak anlamlı olduğu tespit edilmiştir. The Bentler-Bonettnormed fit index (NFI), The Tucker-Lewiscoefficient fit index (TLI) ve diğer uyum indeksleri modelin iyi uyumlu olduğunu göstermektedir (Tablo-1). Modelde bulunan endogenous verileri arasında iki yönlü korelasyonların her biri yüksek değerlere sahiptir ve istatistiksel olarak anlamlı olduğu görülmektedir.

Tablo 2. Yaptsal Eşitlik Modelinin Uyumuna İlişkin İstatistiksel Değerler

\begin{tabular}{llll}
\hline Ölçüm & $\dot{\text { İy Uyum }}$ & Kabul Edilebilir Uyum & Modelin Uyum İndeksi Değerleri \\
\hline$(\mathrm{X} 2 / \mathrm{sd})$ & $\leq 3$ & $\leq 4-5$ & 2.58 \\
\hline RMSEA & $\leq 0.05$ & $0.06-0.08$ & 0.08 \\
\hline SRMR & $\leq 0.05$ & $0.06-0.08$ & 0.07 \\
\hline GFI & $\geq 0.90$ & $0.89-0.85$ & 0.94 \\
\hline AGFI & $\geq 0.90$ & $0.89-0.85$ & 0.89 \\
\hline
\end{tabular}

Tablo 2'de gösterilen uyum değerlerini incelediğimizde, $\mathrm{x}^{2} / \mathrm{sd}=2.58$, $\mathrm{SRMR}=0.08, \mathrm{SRMR}=0.07, \mathrm{GFI}=0.94, \mathrm{AGFI}=0.89$. olduğunu görmekteyiz. Modelin genelinde istenen düzeyde iyi uyum değerlerinin tespit edildiği görülmektedir (Bollen, 1989; Browne ve Cudeck, 1993; Byrne, 2010; Hu ve Bentler, 1999; Kline, 2011; Tanaka ve Huba, 1985). Analiz edilen tek faktörlü model Şekil 1'de gösterilmektedir. Modelde gösterilen bütün yolların 0.01 düzeyinde anlamlı olduğu görülmektedir. 


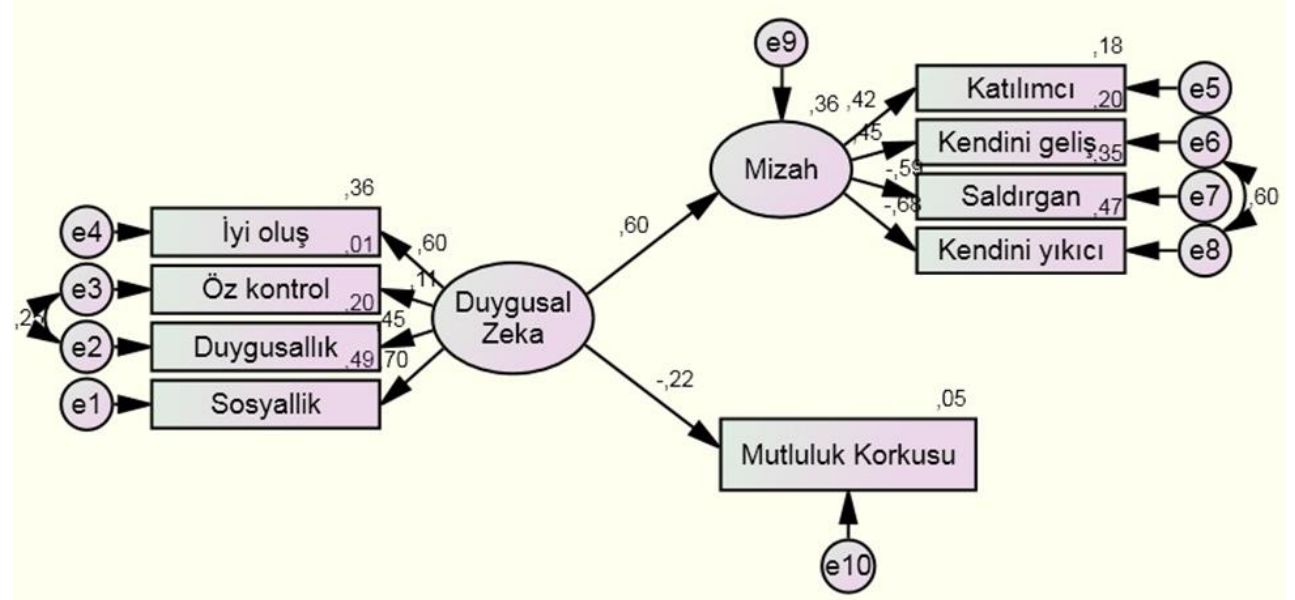

Şekil-1: Modele İlişkin Yol Analizi

Tablo 3. Ergenlerde Duygusal Zekâ, Mutluluk Korkusu ve Mizah Tarzlarn Arasındaki Yordayıcı İlişkilere Yönelik Model

\begin{tabular}{lllll}
\hline Yordayıcı Değişken & Bağımlı Değişken & Doğrudan Etki & Standart Hata & Kritik Değer \\
\hline Duygusal Zeka & Mizah & 0.60 & 0.17 & $3.57^{*}$ \\
\hline Duygusal Zeka & Mutluluk Korkusu & -0.22 & 0.20 & $-2.51^{*}$ \\
\hline
\end{tabular}

${ }^{*} \mathrm{p}<0.01$.

Değişkenler arasındaki yordayıcı ilişkiler incelendiğinde; Mizahı etkileyen önemli bağımsız değişkenin $(t=3.57, p<0.01)$ duygusal zekâ değişkeni olduğu görülmektedir. Bu faktöre ait bağlantı katsayı değeri $\beta=0.60$ olarak bulunmuştur. Ergenlerin duygusal zekâları ile mizah tarzları arasındaki yordayıcı ilişkiler incelendiğinde, pozitif yönde anlamlı doğrusal bir ilişkinin olduğu görülmektedir. Bir başka ifadeyle elde edilen bulgular, ergenlerde duygusal zekânın artmasıyla mizah duygusunda da artış olacağını göstermektedir.

Modelde mutluluk korkusunu etkileyen değişkenin $(t=-2.51, p<0.01)$ duygusal zekâ olduğu görülmektedir. Bu faktöre ilişkin bağlantı katsayı değeri $\beta=-0.22$ olarak ortaya konmuştur. Ergenlerin mutluluk korkuları ve duygusal zekâları arasındaki yordayıcı ilişkiler incelendiğinde, negatif yönde doğrusal bir ilişki olduğu görülmektedir. Diğer bir ifadeyle elde edilen bulgular, ergenlerin duygusal zekâları arttıkça mutluluk korkularının azalacağını ortaya koymaktadır. 


\section{Tartışma}

Yapılan çalışmadan elde edilen bulgulara göre, ergenlerin duygusal zeka düzeyleri arttıkça mizah duygularının da arttığı görülmüş̧ür. Yapılan benzer araştırmalar incelendiğinde, Tümkaya, Hamarta, Deniz, Çelik ve Aybek (2008) yaptıkları çalışmada benzer şekilde duygusal zekanın katılımcı, kendini geliştirici, saldırgan ve kendini yıkıcı mizah tarzını yordadığı ortaya çıkmıştır.

Katılımcı mizah tarzına sahip insanların mutlu, çevresindekilere saygılı ve uyum içinde olması (Martin ve diğ., 2003) ve kendini geliştirici mizaha sahip bireylerin ise gergin oldukları durumlarda mizahı kullanmaları ve bu sayede stresin üstesinden gelebilmeleri ile karakterize edilmiştir (Kazarian ve Martin, 2004). Vernon ve ark. (2009) yaptıkları çalışmada bireylerin mizah tarzları ile duygusal zeka düzeylerinin birbirini yordadığını ve aralarında anlamlı bir ilişkinin olduğunu belirtmektedir.

Yıkıcı mizahın, kaygı ve üzüntü gibi negatif duygularla pozitif yönde; psikolojik iyi olma, benlik saygısı ve ilişki doyumu gibi pozitif duygularla negatif yönde bir ilişkinin olduğu belirtilmektedir (Yerlikaya, 2003). Aynı zamanda benzer şekilde, Tümkaya, Hamarta, Deniz, Çelik ve Aybek (2008) çalışmalarında duygusal zeka seviyesi düşük bireylerin kendini yıkıcı mizaha daha yatkın olduklarını ortaya koymaktadırlar. Oğurlu (2015) ‘da duygusal zekanın uyumlu mizah türleri ile pozitif yönde ilişkili olduğunu dile getirmiştir.

Buradan yola çıkarak yapılan bu çalışmanın literatürdeki diğer çalışmalarla benzerlik gösterdiği görülmektedir. Bireylerin duygusal zeka seviyelerinin yüksek olması onların yaşadığı duyguları tanımasına, yaşadığı toplumda ve ilişkilerinde daha uyumlu olmasına ve aynı zamanda genel ruh durumu açısından sağlıklı olmasına neden olmaktadır. Bununla beraber birey duygusal zeka ile hayata pozitif ve mizah yoluyla bakma arasında pozitif yönlü bir ilişkinin olduğu, kötümser olma ve fazla stresli olma arasinda ise negatif yönde bir ilişkinin olduğu ifade edilmektedir (Hugelshofer, Know, Reff ve Olson, 2006).

Araştırmadan elde edilen diğer bir bulgu olan, ergenlerin mutluluk korkuları ile duygusal zeka düzeyleri arasındaki yordayıc ilişki incelendiğinde, mutluluk korkusu ile duygusal zeka arasında negatif yönde anlamlı bir ilişkinin olduğu tespit edilmiştir. Diğer bir ifadeyle, bireylerde duygusal 
zeka düzeyi yükseldikçe mutluluk korkusunun azaldığ1 görülmektedir. Bireyler duygularını çevresindekilerle paylaşabildiği, hissedebildiği ve kolaylıkla ilişki kurabildiği zaman mutlu olur ve psikolojik olarak doyum sağlar. Bu da ancak duygusal zeka ile mümkün olur (Tümkaya, Hamarta, Deniz, Çelik ve Aybek, 2008).

Mutlulukla ilgili literatüre bakıldığında yapılan çalışmaların yoğun olarak Batı toplumlarının kültürel özelliklerini ve değerlerini temel aldığı görülmektedir (Joshanloo, 2014). Batı toplumlarında mutluluk bireylerin yaşamına şekil veren en yüksek değer olarak görülmekte ve kişisel bir kavram olarak ele elınması gerektiği savunulmaktadır (Joshanloo ve Weijers, 2013). Fakat her kültürde kişisel mutluluğa verilen önem aynı değildir ve yapılan araştırmalarda doğu kültüründe bireylerin mutluluklarının bireysel başarılara bağlı olmayıp, kişiler arası ilişkiler üzerinden değerlendirildiği görülmektedir (Morris, 2012). Suh (2000), yaptığı çalışmasında batılıların mutlu olmaya yönünde, orta asyalıların ise sosyal ahenk ve aidiyet konusunda oldukça fazla baskı hissettikleri sonucuna ulaşmıştır. Orta asyalılar arasında bireysel mutluluğun öncelenmesinin sosyal ahengi bozduğuna yönelik inanışlara rastlanmıştır.

Yapılan incelemeler sonucunda, mutluluk korkusu kavramı ile ilgili günümüzde sinırlı sayıda çalışma bulunduğu görülmektedir. Bu sebeple duygusal zeka ile mutluluk, yaşam doyumu, öznel iyi oluş arasındaki ilişkileri içeren çalışmalar incelenmiştir. Furnham ve Petrides (2003), yaptıkları çalişmada duygusal zeka ve mutluluk arasında pozitif yönlü bir ilişki olduğunu saptamışlardır. Benzer şekilde, Constantine ve Gainor (2001) duygusal zekanın empati, benlik algısı, sözel zeka ve yaşam doyumu ile pozitif yönde ilişkili olduğunu belirtmektedirler. Zeidner, Matthevus ve Roberts (2009), duygusal zekanın sosyal- duygusal başarı, pozitif duygulanım, yaşam memnuniyeti, özsaygı, yüksek yaşam doyumu, artan sosyallik ve iyi oluş ile arasında pozitif yönlü anlamlı bir ilişkinin olduğunu belirtmektedir.

Buradan yola çıkarak yapılan bu çalışmadan elde edilen bulgunun literatürde incelenen diğer çalışmalarla paralellik gösterdiği görülmüştür. Duygusal zekanın yüksek olduğu bireylerde mutluluk ve yaşam memnuniyetinin de yüksek olması, bu araştırmanın konusu olan mutluluk korkusunun da az olduğunu bizlere göstermektedir. Duygusal zekası yüksek bireyler duygularını yönetebilen, olumsuz duyguları kabul eden, onları yok saymayıp saygıyla karşılayan ve dolaylı olarak mutluluğa erişen bireylerdir. Dola- 
yısıyla mutluluktan korkan bireylerde duygusal zekanın daha düşük olması beklenen bir sonuçtur.

\section{Sonuç ve Öneriler}

Değişkenler arasındaki yordayıcı ilişkiler incelendiğinde; mizahı etkileyen önemli bağımsız değişkenin duygusal zekâ değişkeni olduğu görülmektedir. Aynı zamanda modelde mutluluk korkusunu etkileyen önemli diğer değişkenin duygusal zekâ olduğu görülmektedir.

Bu çalışma sadece İstanbul ilinde lise düzeyinde öğrenim 14-18 yaşlar arası ergenler ile sınırlı tutulmuştur. Gelecekte yapılacak çalışmalar, farklı eğitim kademelerinde yürütülebileceği gibi, yetişkinleri veya özel grupları da kapsayacak şekilde genişletilebilir. Aynı şekilde yapılan bu çalışma İstanbul ilinde yapılmaıştır. Bu değişkenlerin farklı illerde de uygulanarak genişletilmesi alanyazına katkı sağlayacağı düşünülmektedir. Mutluluk ve öznel iyi oluş ile ilgili çalışmalar günümüzde oldukça yaygin olsa da mutluluk korkusu ve öznel iyi oluş, öz şefkat veya psikolojik iyi oluş ile ilgili çalışmaların pek fazla olmadığı tespit edilmiştir. Bu kavrama ilişkin bu bahsedilen değişkenlerle veya özel belirlenmiş gruplarla yeni çalışmaların yapılmasının alana önemli katkılarının olacağı düşünülmektedir. 


\title{
EXTENDED ABSTRACT
}

\section{Investigation of the Predictive Relationship Between Emotional Intelligence, Fear of Happiness and Humor Styles in Adolescents}

\author{
Zafer Baş - Ayşegül Baş - Ahmet Kalafat - Bülent Dilmaç \\ Ministry of National Education, Necmettin Erbakan University
}

Adolescence, which is an important transition period of human life, brings with it many changes. The individual undergoes many changes both physically and psychologically. In this process, it is very important for the individual to recognize and manage his / her emotions. In recent years, studies have been conducted on how students perceive themselves with regard to emotional intelligence and emotional competence levels. Happiness, on the other hand, plays a role in nurturing the psychological aspect of the individual in this developmental period. However, the belief that being happy in some individuals will have some negative consequences has led to a concept that we call fear of happiness. Fear of happiness also affects humor styles in adolescents. This study was conducted to investigate the predictive relationship between emotional intelligence, fear of happiness and humor styles in adolescents.

In this study, which has a quantitative research paradigm, it was aimed to determine the relationships between emotional intelligence, fear of happiness and humor styles in adolescents and to test the relationships between these variables with structural equality model. For this purpose, the research was carried out according to the relational survey model which is a sub-type of the general survey model. The study group of the study consisted of 226 high school students 136 (60.2\%) female and 90 (39.8\%) male) in Istanbul. The age of the students ranged between 14 and 18 years. In the research, Emotional Intelligence Property Scale-Short Form, Fear of Happiness Scale and Humor Styles Scale were used as data collection tools.

When the predictive relations between emotional intelligence and humor styles of adolescents are examined, it is seen that there is a significant positive linear relationship. In other words, the findings indicate that adoles- 
cents will increase their emotional intelligence with increasing sense of humor. When the predictive relationships between happiness fears and emotional intelligence of adolescents are examined, it is seen that there is a negative linear and significant relationship. In other words, as the emotional intelligence of adolescents increases, the fears of happiness will decrease. From this point of view, increasing the level of emotional intelligence in the individual will increase the sense of humor and fear of happiness in the field of thinking that group guidance studies can be done in this area.

When the goodness of fit indices of structural equation model were examined, it was seen that good fit was realized; $\mathrm{x} 2$ / sd $=2.58, \mathrm{SRMR}=0.08$, $\mathrm{SRMR}=0.07, \mathrm{GFI}=0.94, \mathrm{AGFI}=0.89$. When the predictive relationships between variables were examined; The most important independent variable affecting humor ( $t=3.57, \mathrm{p}<0.01)$ appears to be the emotional intelligence variable. The correlation coefficient value of this factor was found to be $\beta=0.60$. When the predictive relations between emotional intelligence and humor styles of adolescents are examined, it is seen that there is a significant positive linear relationship. In other words, the findings suggest that adolescents will increase their emotional intelligence by increasing their sense of humor. In the model, another important variable affecting the fear of happiness $(t=-2.51, p<0.01)$ appears to be emotional intelligence. The correlation coefficient value for this factor was determined as $\beta=-0.22$. When the predictive relationships between happiness fears and emotional intelligence of adolescents are examined, it is seen that there is a negative linear and significant relationship. In other words, as the emotional intelligence of adolescents increases, the fears of happiness will decrease.

When similar studies were examined, it was revealed that there were significant relationships between emotional intelligence and humor styles and they predicted each other (Tümkaya et al. (2008); Vernon et al. (2009)). Likewise, in the study of Oğurlu (2015), it was seen that emotional intelligence was positively associated with compatible humor types.

Again, similar studies with a negative significant relationship between emotional intelligence, another finding obtained, and fear of happiness, were examined. Furnham and Petrides (2003) found a positive relationship between emotional intelligence and happiness in their study. Similarly, Zeidner, Matthevus, and Roberts (2009) state that emotional intelligence is positively associated with social-emotional achievement, positive affect, life 
satisfaction, self-esteem, higher life satisfaction, increased sociability and well-being. Based on this, it has been observed that the findings obtained from this study are in parallel with other studies examined in the literature.

The high happiness and life satisfaction in individuals with high emotional intelligence shows us that the fear of happiness, which is the subject of this study, is less. Individuals with high emotional intelligence are individuals who are able to manage their emotions, accept negative emotions, respect them without ignoring them, and reach happiness indirectly. Therefore, it is an expected result that emotional intelligence is lower in individuals who are afraid of happiness.

\section{Kaynakça / References}

Constantine, M.G. ve Gainor, K.A.(2001). Emotional intelligence and empathy: Their relation to multi-cultiral counselling knowledge and awareness. Professional School Counselling, 5(2),131-137.

Çakar, U., ve Arbak, Y. (2004). Modern yaklaşımlar ışığında değişen duygu-zeka ilişkisi ve duygusal zeka. Dokuz Eylül Üniversitesi Sosyal Bilimler Enstitüsü Dergisi, 6 (3), 23-48.

Demirci, I., Halil, E. K. Ş. İ., Kardaş, S., ve Dinçer, D. (2016). Mutluluk korkusu ölçeği'nin Türkçe formunun geçerlik ve güvenirliği. Kastamonu Ĕ̈itim Dergisi, 24(4), 2057-2072.

Deniz, M. E., Özer, E., ve Işık, E. (2013). Duygusal zekâ özelliği ölçeği-kısa formu: geçerlik ve güvenirlik çalışması. Eğitim ve Bilim, 38(169), 407-419.

Diener, E. (1994). Assessing subjective well-being: Progress and opportunities. Social Indicators Research, 31(2), 103-157.

Furnham, A., ve Petrides, K. V. (2003). Trait emotional intelligence and happiness. Social Behavior and Personality: an international journal, 31(8), 815-823.

Gilbert P, McEwan K, Catarino F, Baiao R, Palmeira L. (2014). Fears of happiness and compassion in relationship with depression, alexithymia, and attachment security in a depressed sample. BritishJournal of Clinical Psychology, 53, 228-244.

Goleman, D. (2000). İs başında duygusal zeka. İstanbul: Varlık Yayınları.

Hugelshofer, D. S., Kwon, P., Reff, R. C. ve Olson, M.L. (2006). Humour's role in the realtion between attributional style and dysphoria. European Journal of Personality, 20, 325-336.

Joshanloo, M. (2014). Eastern conceptualizations of happiness: Fundamental differences with Western views. Journal of Happiness Studies, 15(2), 475-493. 
Joshanloo, M. ve Weijers, D. (2013). Religiosity's moderation effect on the relationship between inequality and subjective well-being across the globe. Unpublished Manuscript.

Joshanloo, M. (2013). The influence of fear of happiness beliefs on responses to the satisfaction with life scale. Personality and Individual Differences, 54, 647-651.

Joshanloo, M. (2014). Differences in the endorsement of various conceptions of wellbeing between two Iranian groups. Psycholog Relig Spiritual, 6, 138-149.

Joshanloo, M, Weijers, D. (2014). Aversion to happiness across cultures: a review of where and why people are averse to happiness. J Happiness Stud, 15, 717-735.

Joshanloo M., Lepshokova Z. K., Panyusheva T., Natalia A., Poon W., Yeung V. W. (2014). Cross-cultural validation of fear of happiness scale across 14 national groups. J Cross Cult Psychol, 45, 246-264.

Karasar, N. (2015). Bilimsel araştrma yöntemi. Ankara: Nobel.

Kazarian,S.S. ve Martin,R.A. (2004). Humour styles, personality, and well-being among lebanese university students. Europen Journal of Personality, 18, 209219.

Martin, R. A. (2001). Humor, Laughter and physical health:Methodological issues and research findings. Psychological Bulletin, 127, 504-519.

Martin, R. A. (2003). Sense of humor. S. J. Lopez, C. R. Snyder (Ed.), Possitive psycholohical assesment. A handbook of model and measures, içinde (s.313-326). Washington. DC: American Psychological Association.

Martin, R. A., Puhlik-Doris P., Larsen G., Gray J., ve Weir K. (2003). Individual differences in uses of humor and their relation to psychological well-being: development of the humor styles questionnaire. Journal of Research in Personality, 37, 48-75.

Mayer, J.D., ve Salovey, P. (1993). The intelligence of emotional intelligence. İntelligence. $17,433-442$.

Morris, S. (2012). The science of happiness: A cross-cultural perspective. H. Selin ve G. Davey (Eds.), Happiness across cultures içinde (Vol. 6, s.435-450). Netherlands: Springer.

Oğurlu, Ü. (2015). Relationship between cognitive intelligence, emotional intelligence and humor styles. International Online Journal of Educational Sciences, 7(2).

Oral, T. (1998). Yaza çize. İstanbul: İris Yayınları

Oruç, Ş. (2010). Sosyal Bilgiler öğretiminde mizah kullanımmn öğrencilerin akademik başarılarına ve tutumlarına etkisi. Mehmet Akif Ersoy Üniversitesi Sosyal Bilimler Enstitüsü Dergisi, 2(3), 58. 
Özdemir S., Sezgin F., Kaya Z., Recepoğlu E. (2011). İköğretim okulu öğretmenlerinin stresle başa çıkma tarzları ile kullandıkları mizah tarzları arasındaki ilişki. Kuram ve Uygulamada Ĕ̈itim Yönetimi. 17(3), 405-428.

Özdemir, M. (2015). Eğitim fakültesi öğrencilerinin duygusal zekalarn ile yaşam doyumlarnnn incelenmesi. Yüksek Lisans Tezi. Atatürk Üniversitesi, Erzurum.

Petrides, K. V., ve Furnham, A. (2000a). On the dimensional structure of emotional intelligence. Personality and Individual Differences, 29, 313-320.

Schumacker, R. E. ve Lomax, R. G. (2004). A Beginner's guide to structural equation modelling. London: Lawrence Erlbaum Associates, Publishers.

Stein, S. J. And Book, H. E. (2003). Eq: Duygusal zeka ve başarını sırn. (Çev. M. Işı). İstanbul: Özgür Yayınları.

Suh, E. M. (2000). Self: The hyphen between culture and subjective well-being. E. Diener ve E. M. Suh (Eds.), Culture and subjective well-being İçinde (s.63-86). Cambridge, MA: MIT Press.

Tümkaya, S., Hamarta, E., Deniz, M. E., Çelik, M. ve Aybek, B. (2008). Duygusal zekâ mizah tarzı ve yaşam doyumu: üniversite öğretim elemanları üzerine bir araştırma. Türk Psikolojik Danışma ve Rehberlik Dergisi, 30(3), 1-18.

Türk Dil Kurumu (TDK) (2019). Türk Dil Kurumu sözlüğ̈̈. http://www.tdk.gov.tr adresinden erişilmiştir..

Uichida, Y. ve Oishi, S. (2016). The happiness of individuals and the collective. Journal of Happiness Studies, 58, 125-141.

Veenhoven, R. (1996). Developments in satisfaction-research. Social Indicators Research, 37(1), 1-46.

Vernon, P. A., Villani, V. C., Schermer, J. A., Kirilovic, S., Martin, R. A., Petrides, K. V.,..., Cherkas, L. F. (2009). Genetic and environmental correlations between trait emotional intelligence and humor styles. Journal of Individual Differences, 30(3), 130-137.

Weisinger, H. (1998). İş yaşamında duygusal zeka. MNS Yayınları: İstanbul.

Yerli, S., (2009). İlk ve orta öğretim okullarnndaki yöneticilerin duygusal zeka ve problem çözme becerileri arasındaki ilişki: İstanbul Anadolu Yakası örneği. Yüksek Lisans Tezi Maltepe Üniversitesi, İstanbul.

Yerlikaya, E. E. (2003). Mizah tarzlan ölçeği (Humor styles questionnaire) uyarlama çalışması.Yayımlanmamış yüksek lisans tezi. Çukurova Üniversitesi, Adana.

Yerlikaya, E. E. (2003). Mizah tarzları ölçeğinin uyarlama çalışması. Yayınlanmamış Yüksek Lisans Tezi. Çukurova Üniversitesi Sosyal Bilimler Enstitüsü, Adana.

Yiğit R (2013) Öğretmen adaylarının öznel iyi oluşu ile sosyal problem çözme beceriler arasındaki ilişkinin incelenmesi. İlköğretim Online, 12, 550-560. 
Ergenlerde Duygusal Zekâ, Mutluluk Korkusu ve Mizah Tarzları Arasındaki Yordayıcı İlişkinin İncelenmesi

Zeidner, M., Matthews, G. ve Roberts, R. D. (2009). What we know about emotional intelligence: How it affects learning, work, relationships, and our mental health. London: The MIT Press.

Kaynakça Bilgisi / Citation Information

Baş, Z., Baş, A. , Kalafat, A. ve Dilmaç, B. (2021). Ergenlerde duygusal zekâ, mutluluk korkusu ve mizah tarzları arasındaki yordayıcı ilişkinin incelenmesi. OPUS-Uluslararası Toplum Araştırmaları Dergisi, 17(33), 154-173. DOI: 10.26466/opus.694580 